\section{In vitro effect of experimental nanocomposites solutions on the prevention of dental caries around orthodontic brackets}

\author{
Karla Lorene de França Leite ${ }^{1}$, Thiago Isidro Vieira ${ }^{1}$, Adílis Kalina \\ Alexandria $0^{2}$, Raphael Ferreira da Silva $0^{3}$, Aline Saddock de Sá Silva \\ $0^{4}$, Ricardo Tadeu Lopes ${ }^{4}$, Andréa Fonseca-Gonçalves ${ }^{1}$, Aline de \\ Almeida Neves ${ }^{1}$, Lúcio Mendes Cabral@², Matheus Melo Pithon $0^{5}$, \\ Yuri Wanderley Cavalcanti ${ }^{6}$, Lucianne Cople Maia ${ }^{1}$.
}

This study aimed to evaluate the in vitro effect of a single application of experimental nanocomposite solutions on the prevention of dental caries around orthodontic brackets. The specimens were exposed to mesoporous silica (MS) nanocomposites containing fluoride by association with titanium tetrafluoride $\left(\mathrm{TiF}_{4}\right)$ or sodium fluoride $(\mathrm{NaF})$. Nanocomposites also could contain calcium and groups were described as $\mathrm{MSCaTiF}_{4}, \mathrm{MSTiF}_{4}$, MSCaNaF, MSNaF, and controls $\left(\mathrm{TiF}_{4}\right.$, and $\left.\mathrm{NaF}\right)$. Specimens were subjected to the formation of a multispecies biofilm to generate a cariogenic challenge. After $24 \mathrm{~h}$, both $\mathrm{pH}$ and total soluble fluoride concentration of the culture medium were assessed. Mineral loss was evaluated by percentage of surface mineral loss $(\% \mathrm{SML})$, mineral volume variation $(\triangle \mathrm{Z})$ of inner enamel and polarized light microscopy (PL). Linear (Ra) and volumetric (Sa) surface roughness and scanning electronic microscopy (SEM) were used to assess enamel topography. Statistical analyses were conducted considering $\mathrm{p}<0.05$. $\mathrm{MSNaF}$ had the highest value of culture medium $\mathrm{pH}$ after cariogenic challenge, similarly to $\mathrm{MSTiF}_{4}$. All nanocomposite solutions released less fluoride than their controls $\mathrm{NaF}$ and $\mathrm{TiF}_{4}(\mathrm{p}<0.05)$. All nanocomposite solutions presented lower \%SML compared to their respective control groups $(\mathrm{p}<0.05)$. Lower $\mathrm{Ra}, \mathrm{Sa}$ and $\Delta \mathrm{Z}$ were observed for experimental groups compared to $\mathrm{TiF}_{4}(\mathrm{p}<0.05)$. The results were confirmed by PL and SEM analysis. The experimental nanocomposite solutions contributed for lower enamel demineralization around orthodontic brackets.

\author{
${ }^{1}$ Department of Pediatric Dentistry and \\ Orthodontics, School of Dentistry, \\ Universidade Federal do Rio de Janeiro, Rio de \\ Janeiro, RJ, Brasil; \\ ${ }^{2}$ Department of Drugs and Medicines, School \\ of Pharmacy, Universidade Federal do Rio de \\ Janeiro, Rio de Janeiro, RJ, Brasil; \\ ${ }^{3}$ Department of Community and Preventive \\ Dentistry, School of Dentistry, Universidade do \\ Estado do Rio de Janeiro (UERJ), Rio de \\ Janeiro, Brasil \\ ${ }^{4}$ Institute of Biophysics Carlos Chagas Filho, \\ Universidade Federal do Rio de Janeiro, Rio de \\ Janeiro, RJ, Brasil; \\ ${ }^{5}$ Department of Healthy I, Universidade \\ Estadual do Sudoeste da Bahia, Jequié, BA, \\ Brasil; \\ ${ }^{6}$ Department of Clinical and Social Odontology, \\ School of Dentistry, Universidade Federal da \\ Paraíba, João Pessoa, PB, Brasil. \\ Correspondence: Lucianne Cople Maia; School \\ of Dentistry, Universidade Federal do Rio de \\ Janeiro, Rua Rodolpho Paulo Rocco, 325. \\ Cidade Universitária, RJ, CEP: 21.941-913, \\ Brasil; Tel.: +55 212562 2098; \\ rorefa@terra.com.br
}

Key Words: Nanotechnology; Fluorides; Orthodontic Brackets; Dental Biofilm.

\title{
Introduction
}

Patients who wear fixed orthodontic appliances may have problems with dental hygiene because of biofilm accumulation (1). Poor hygiene puts patients at risk for the development of carious lesions, and products aimed at reducing demineralization are therefore recommended (2). Decalcification of the enamel surface adjacent to orthodontic brackets, observed in the form of white spot lesions, is frequent well-known side-effect of orthodontic treatment. Fixed orthodontic appliances and the bonding materials increase the biofilm retention and enhance the formation of white spot lesions $(1,2)$. Orthodontic patients at high risk of dental caries should be instructed for appropriate and frequent oral hygiene regime with the use of fluoride-based agents, including the complementary use of mouthwashes to enhance remineralization (3). Therefore, fluoride- and calcium-based products, either in association or alone, have been used to minimize enamel demineralization (4).

In the available literature, nanoparticulated products have caught the attention of researchers, since they can carry a larger number of elements compared to the surface area, modulate availability, have specific action, and improve the stability of the chemical structure (5). Among these composites, mesoporous silica (MS) deserves special attention as its specific surface and porosity properties allow controlling drug delivery and improving drug release kinetics (6).

In general medicine, the association of MS with calcium improved the loading capacity of alendronate particles, efficiently inhibiting the growth of HeLa carcinogenic cells when compared to free alendronate (7). In dentistry, studies have used this nanoparticle in a new method to encapsulate and release CHX from dental composite using MS $(8,9)$, also using CHX-enriched nanoparticles 
against oral biofilms (10). Bioactive glass-coated MS was also used to investigate their effects on dentinal tubule occlusion $(11,12)$, remineralization $(13)$ and against dental erosion $(14,15)$.

However, to the authors' knowledge, no studies have evaluated the incorporation of fluoride on MS-based nanocomposites, with or without calcium, for the prevention of enamel demineralization. Bearing in mind the properties of MS-based nanocomposites (6-15) described above, the association with fluoride and possible incorporation of calcium would contribute towards the prevention/reduction of dental caries lesions. Therefore, this study evaluated in vitro the preventive effect of a single application of experimental MS-based nanocomposite solutions containing fluoride, with and without calcium, on the demineralization of enamel surface around orthodontic brackets.

\section{Materials and Methods}

\section{Study Design}

Given the paucity of previous studies on the topic, this randomized, controlled, single-blind, in vitro study took into account a sample size ( $\mathrm{n}=13$ per group) based on the mineral loss of compounds containing calcium and fluoride $(16,17)$. Therefore, a 0.8 statistical power was used to detect a significant difference of $50 \%$ in average mineral loss in each treatment group when compared to the control group ( $1.36 \%$ of $\mathrm{NaF}$ ), running a one-tailed test at a $5 \%$ significance level (BioEstat $5.3^{\circledR}$, Instituto de Desenvolvimento Sustentável Mamirauá, Tefé, Brazil).

\section{Preparation of the Experimental Nanocomposites}

MS-based nanocomposites were obtained by nanoprecipitation, altering their molar ratio for lyophilization and physicochemical characterization (6). Thereafter, fluoridated titanium tetrafluoride $\left(1 \% \mathrm{TiF}_{4}, 6135 \mathrm{ppm}\right.$ of $\left.\mathrm{F}^{-}\right)$and sodium fluoride $\left(1.36 \% \mathrm{NaF}, 6135 \mathrm{ppm}\right.$ of $\left.\mathrm{F}^{-}\right)$solutions (Aldrich Chemical $\mathrm{Co}^{\circledR}$, Saint Louis, USA) were included, to which calcium (Ca) was added or not. The fluoride concentration within groups was primarily defined according to the $\mathrm{TiF}_{4}$ group, since this substance is more difficult to synthetize. Therefore, all other solutions were manipulated in order to present similar fluoride concentration to that observed in $1 \% \mathrm{TiF} 4$ usually used in clinical practice. The following experimental nanocomposites were produced: $\mathrm{MSCaTiF}_{4}, \mathrm{MSTiF}_{4}, \mathrm{MSCaNaF}$ and $\mathrm{MSNaF}$.

For characterization analyses, the MS-only and MSCa controls were considered. The characterization of these nanocomposites indicated that the MS-only had a mean diameter of $183.18 \pm$ $1.5 \mathrm{~nm}$ and a polydispersion index (PdI) of $0.240 \pm 0.021$, using the scattering technique (DLS) and zeta potential of $-29.66 \pm 0.18 \mathrm{mV}$ (Table 1). In addition, the MS nanoparticle formed were spheroid, according to transmission electron microscopy (TEM) (Figure 1). Infrared spectrum of absorption or emission of nanoparticles was obtained through Fourier-Transform Infrared Spectroscopy (FTIR) and X-ray diffraction pattern of mesoporous silica nanoparticles was evalueted (Figure 2 and 3 ).

Table 1: Characterization of mesoporous silica particles.

\begin{tabular}{c|c|c|c|c|c|c|c}
\hline Groups & $\begin{array}{c}\text { Fluoride } \\
\text { theorists* }^{*}\end{array}$ & $\begin{array}{c}\text { Calcium } \\
\text { concentration } \\
(\boldsymbol{\%})\end{array}$ & $\begin{array}{c}\text { Yield } \\
(\boldsymbol{\%})\end{array}$ & $\begin{array}{c}\text { Z-average } \\
(\mathbf{d} \text {. nm) }\end{array}$ & $\begin{array}{c}\text { Polydispersity } \\
\text { Index } \\
(\mathbf{P d I})\end{array}$ & $\begin{array}{c}\text { Zeta potential } \\
(\mathbf{m V})\end{array}$ \\
\hline $\mathrm{MSCaTiF}_{4}$ & $13,09 \%$ & $11,10 \pm 0,08$ & $55,03 \pm 0,05$ & $185,7 \pm 1,5$ & $0,235 \pm 0,004$ & $6,45 \pm 0,62$ & $-32,28 \pm 0,41$ \\
$\mathrm{MSTiF}_{4}$ & $6,71 \%$ & - & $47,22 \pm 0,03$ & $176,6 \pm 1,3$ & $0,261 \pm 0,007$ & $6,38 \pm 0,03$ & $-30,21 \pm 0,33$ \\
$\mathrm{MSCaNaF}$ & $16,37 \%$ & $11,32 \pm 0,12$ & $58,21 \pm 0,05$ & $188,3 \pm 1,7$ & $0,242 \pm 0,005$ & $6,51 \pm 0,37$ & $-29,71 \pm 0,11$ \\
$\mathrm{MSNaF}$ & $6,57 \%$ & - & $48,63 \pm 0,05$ & $178,2 \pm 1,4$ & $0,223 \pm 0,005$ & $6,82 \pm 0,51$ & $-28,16 \pm 0,28$ \\
$\mathrm{MSCa}$ & - & $5,60 \pm 0,08$ & $43,03 \pm 0,04$ & $187,1 \pm 1,8$ & $0,241 \pm 0,008$ & $6,36 \pm 0,34$ & $-27,96 \pm 0,31$ \\
$\mathrm{MS}-$ Only & - & - & - & $187,8 \pm 4,3$ & $0,250 \pm 0,007$ & $6,11 \pm 0,13$ & $-26,47 \pm 0,22$ \\
\hline
\end{tabular}

* means predicted theoretical values of fluoride theorists for nanocomposites considering the atoms present individually. Value calculated based on the mass of each of the reagents used in the preparation of MS. 


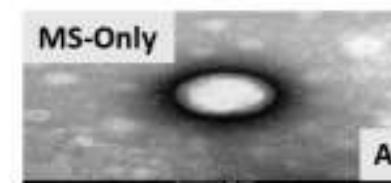

MSCa

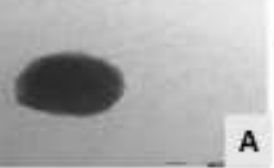

A

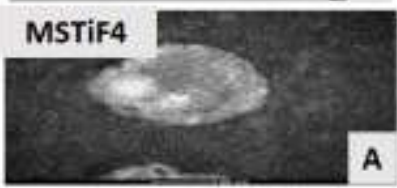

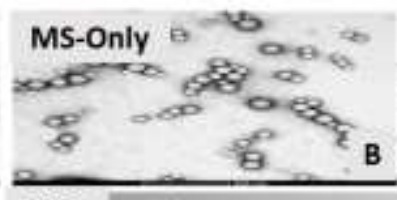

MSCa

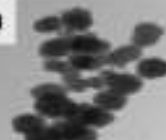

MSTIF4

B

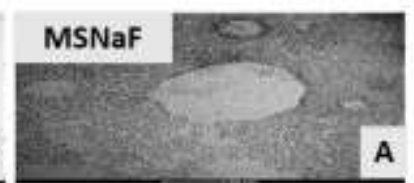

MSCaNaF

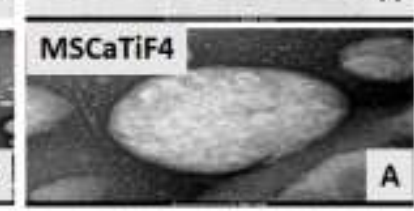

MSNaF

A

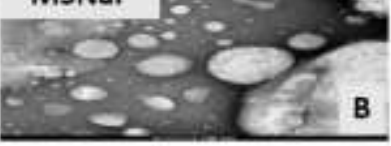

MSCaNaF

A

A

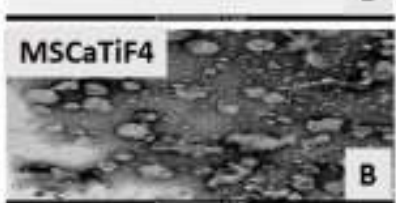

Figure 1: Photomicrographs obtained by TEM analysis of mesoporous silica nanoparticles.

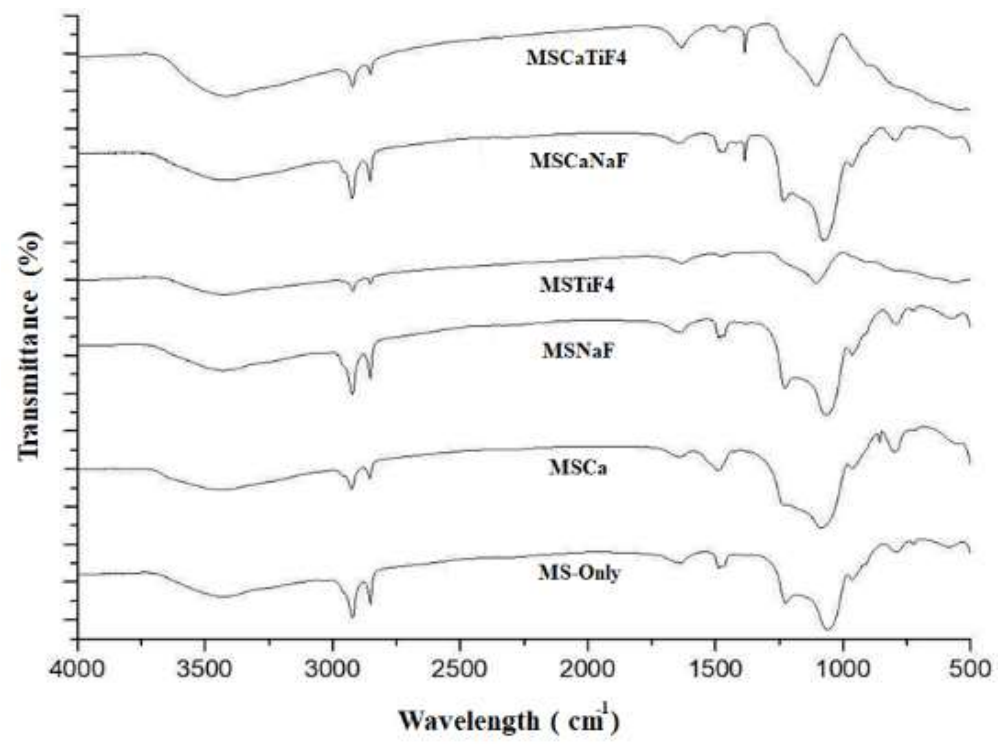

Figure 2: FTIR spectrum of mesoporous silica nanoparticles.

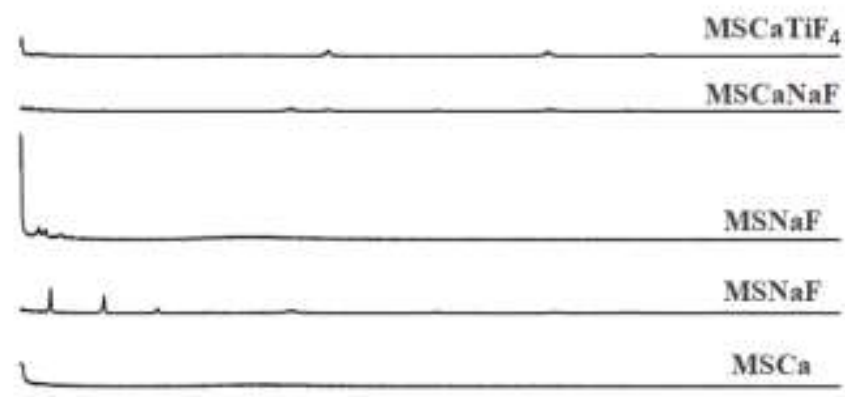

MS-Only

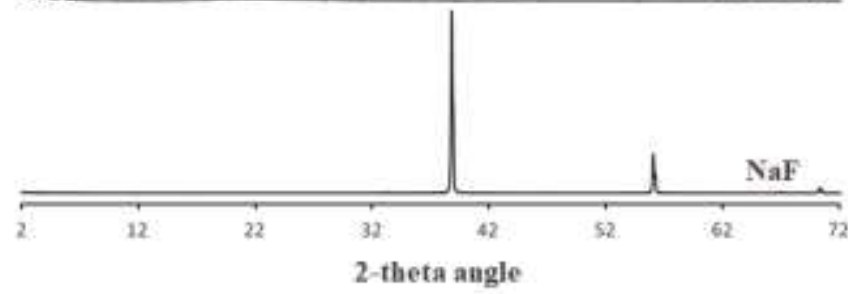

Figure 3: X-ray diffraction pattern of mesoporous silica nanoparticles. 


\section{Specimen Preparation}

Bovine enamel blocks $(8 \times 8 \times 2.5 \mathrm{~mm})$ were obtained from sound bovine incisors and specimens were planned according to previously reported in the literature (18). After that, a window measuring $19.63 \mathrm{~mm}^{2}$, whose surrounding area was protected with an acid-resistant varnish layer (Risqué $^{\circledR}$, São Paulo, Brazil), was exposed. Surface microhardness of the enamel was assessed by a Knoop diamond indenter using a load of $50 \mathrm{~g}$ for $5 \mathrm{~s}$, with three equidistant indentations $(100 \mu \mathrm{m})$ inside the delimited area, close to the margin. Enamel blocks in the $\pm 10 \%$ range were selected according to the total mean of the baseline microhardness.

A single trained operator used the Transbond Plus Self Etching Primer (3M Unitek ${ }^{\circledR}$, Monrovia, USA) and Transbond XT (3M ESPE ${ }^{\circledR}$, Saint Paul, USA) for bonding the metal orthodontic bracket $(3.20$ x $2.70 \mathrm{~mm}$ ) (Edgewise Standard .022", Morelli, Sorocaba, Brazil) to the central area of the window. An orthodontic elastic (intermaxillary elastics 5/16", Morelli, Sorocaba, Brazil) band was placed around the bracket to mimic the clinical setting.

After random distribution of the specimens (Microsoft Excel $\left.{ }^{\circledR}\right)$ into each of the groups ( $\left.n=13\right)$, the specimens were transferred to a 12-well polystyrene plate (model K12-024, Kasvi ${ }^{\circledR}$, São José do Pinhais, Brazil), and then sterilized under ultraviolet light for $1 \mathrm{~h}$ with $40 \mathrm{Watts}$ power (19). The groups were as follows: $\mathrm{MSCaTiF}_{4}, \mathrm{MSTiF}_{4}, \mathrm{TiF}_{4}$ (fluoridated control), MSCaNaF, MSNaF, $\mathrm{NaF}$ (fluoridated control), growth control (GC) and sterility control (SC).

A single blinded researcher actively applied the test products $(100 \mu \mathrm{L})$ for 1 minute in the intervention area around the orthodontic brackets $\left(11 \mathrm{~mm}^{2}\right)$ using a microbrush (KG Sorensen ${ }^{\circledR}$, Cotia, Brazil). After application, specimens were dried at room temperature.

\section{Cariogenic Challenge}

After reactivation of Streptococcus mutans (ATCC 25175), S. salivarius (ATCC 7073), S. sanguinis (ATCC 20556), and Lactobacillus casei (ATCC 393) strains, a bacterial suspension was standardized according to CLSI standards (20). The inoculum consisted of the multispecies biofilm was standardized at a concentration of $1 \times 10^{7} \mathrm{CFU} / \mathrm{mL}$ ( 0.1 absorbance under $625 \mathrm{~nm}$ wavelength).

Prior to biofilm formation, the specimens were submitted to the formation of artificial salivary pellicle (21), with $1 \%$ carboxymethyl, $0.0084 \%$ sodium chloride, $0.12 \%$ potassium chloride, $0.0342 \%$ phosphate monobasic potassium, $0.0146 \%$ calcium chloride, and $0.0052 \%$ magnesium chloride. Specimens were pre-conditioned with artificial saliva for $2 \mathrm{~h}$, at $37^{\circ} \mathrm{C}$, in 24 -well polystyrene culture plates (model K12-024, KasviTM, São José do Pinhais, BRA). After removal of the saliva, $5 \mathrm{~mL}$ of the mixed inoculum $\left(5 \times 10^{5} \mathrm{CFU} / \mathrm{mL}\right.$ of the final concentration) with BHI broth containing $2 \%$ sucrose $(\mathrm{pH}=7.10)$ was added and the specimens were incubated at $37^{\circ} \mathrm{C}$ for $24 \mathrm{~h}$.

GC (growth control) specimens contained bacterial suspension (multispecies biofilm of Streptococcus spp. and Lactobacillus casei) prepared in BHI broth containing 2\% sucrose. SC (sterility control) specimens were incubated in BHI broth with $2 \%$ sucrose, without any microorganism. GC and SC groups did not receive treatment with any of the experimental solutions, nor respective controls $\left(\mathrm{NaF}\right.$ and $\left.\mathrm{TiF}_{4}\right)$.

\section{Data Collection and Analysis}

\section{Analysis of pH and Total Soluble Fluoride in Culture Medium}

After $24 \mathrm{~h}$, the specimens were sonicated for 1 min using an ultrasonic cleaner to remove any remaining residues and then the brackets were debonded manually. Acidogenicity of the culture medium was assessed by measuring the $\mathrm{pH}$ of the culture medium using an electrode connected to a $\mathrm{pH}$ meter $\left(\mathrm{PHOX}^{\circledR}\right.$, Colombo, Brazil). The procedure was carried out in duplicate by a blinded trained examiner.

The total soluble fluoride (TSF) concentration in the culture medium was determined using a fluoride ion selective electrode (Orion 9609) coupled to a potentiometer (Orion Star Series, Termo Fisher Scientific ${ }^{\circledR}$, Waltham, USA). Aliquots $(2 \mathrm{~mL})$ from culture medium were read at a $1: 1(\mathrm{v} / \mathrm{v})$ ratio using a TISAB II solution after obtaining low-concentration $(0.06$ to $1 \mu \mathrm{g} \mathrm{F}$ - / mL [r2 $=0.994$; slope $=-58.9])$ and high-concentration $(1$ to $32 \mu \mathrm{g} \mathrm{F}-/ \mathrm{mL}$ [r2 = 0.999; slope $=-59.6])$ standard curves. 


\section{Mineral Loss Analysis}

All enamel blocks of each group were reassessed after cariogenic challenge by the same blinded and trained examiner to determine the final surface microhardness, in order to obtain the percentage of surface mineral loss (\%SML) after the experiment (23). The \%SML was calculated using the specimens' surface microhardness ( $\mathrm{SM}$, expressed in $\mathrm{kg} / \mathrm{mm}^{2}$ ), measured before product application and after experiments. The \%SML was obtained by the following formula:

$$
\% \text { SML }=100 \times \frac{(\text { SMbaseline }- \text { SM final })}{\text { SMbaseline }}
$$

For a volumetric analysis of mineral content in the lesion, randomly selected enamel blocks $(\mathrm{n}=6$, per group) were scanned on a high-energy micro-CT scanner (Skyscan 1173, Bruker, Kontich, Belgium) using the following acquisition parameters: $70 \mathrm{kVp}, 114 \mathrm{~mA}$, pixel size of $7.12 \mu \mathrm{m}$, and 1$\mathrm{mm} \mathrm{Al}$ filter. The images were later reconstructed into cross-sections using a proprietary software (NRecon, Bruker) and specific reconstruction parameters. Mineral loss was then determined by the integrated mineral loss analysis $(\Delta \mathrm{Z})$ in volumes of interest (VOI) selected from each specimen. After averaging gray values in each VOI, a linear profile was drawn across the enamel surface and the integrated area under the curve corresponding to the carious lesion was calculated. This represents the net mineral loss of the lesion (24).

A qualitative analysis of demineralization was performed using Polarized Light Microscopy. Randomly selected enamel blocks ( $\mathrm{n}=2$, per group) were sectioned longitudinally with a diamond disc (Isomet, model 11-1280-170, Lake Bluff ${ }^{\circledR}$, Illinois, USA). Slices of approximately $300 \mu \mathrm{m}$ were cut and then laterally worn to approximately $100 \mu \mathrm{m}$, using aluminum oxide sandpaper at granulation \#600. After that, samples were stored in microtubes with $0.02 \%$ sodium azide solution for $72 \mathrm{~h}$ at $4{ }^{\circ} \mathrm{C}$ in order to keep them hydrated and to avoid the growth of fungi and bacteria for analysis of subsurface mineral loss under a polarized light microscope (Axioskop 40, Carl Zeiss ${ }^{\circledR}$, Oberkochen, Germany) equipped with a 10x objective lens and 550-nm phase contrast filter (red filter I). The images were photographed with a digital camera (44 D7000, Nikon ${ }^{\circledR}$, Tokyo, Japan) under the same lighting conditions. The distilled and deionized water was the environment used to analyze the change in enamel refraction, as indicative of the demineralization occurring on the surface of the block. Dental demineralization was observed as a dark area/band on the cross-sectional surface of specimen.

\section{Surface Topography Analysis}

Surface topography of the enamel in the regions around the bracket debonding area of all specimens ( $\mathrm{n}=13$ per group) was assessed by 3D non-contact profilometry (Nanovea PS50 Optical, NANOVEA ${ }^{\circledR}$, Irvine, USA). A standardized $1-\mathrm{mm}^{2}$ assessment area was established on the enamel specimen. The mean value from three linear roughness $(\mathrm{Ra})(500 \mu \mathrm{m})$ measurements and three volumetric roughness $(\mathrm{Sa})\left(250 \mu \mathrm{m}^{2}\right)$ measurements were obtained for each specimen.

A qualitative analysis of surface topography was performed using Scanning Electron Microscopy (SEM). Specimens ( $\mathrm{n}=2$ per group) were gold-sputtered prior to SEM visualization. SEM (Fei Quanta $250^{\circledR}$, Termo Fisher Scientific ${ }^{\circledR}$, Waltham, USA) was operated at $20 \mathrm{kV}$. The area between the resin remnant after bracket debonding and the sound enamel surface was examined. Photomicrographs were obtained at 5.000x magnification. Both profilometry and SEM evaluations were carried out by a single blinded examiner.

\section{Statistical Analysis}

The data were statistically analyzed by SPSS version 20.0 (IBM ${ }^{\circledR}$, Chicago, USA) using a 5\% significance level. The data distribution was evaluated by the Shapiro-Wilk test. The Kruskal-Wallis and Mann-Whitney tests were used for the analyses of $\mathrm{pH}$, TSF, \%SML, profilometry parameters, and $\Delta \mathrm{Z}$ values. 


\section{Results}

Treatment with MSNaF resulted in the highest value of culture medium $\mathrm{pH}$ after the cariogenic challenge and was similar to $\mathrm{MSTiF}_{4}$. As for the TSF of the culture medium the experimental nanocomposites released less fluoride than their controls $\mathrm{NaF}_{\text {and }} \mathrm{TiF}_{4}(\mathrm{p}<0,05)$ (Table 2).

Table 2: $\mathrm{Ph}$, total soluble fluoride, microhardness, mineral loss analysis $(\Delta \mathrm{Z})$ and profilometry analysis (Ra and $\mathrm{Sa})$.

\begin{tabular}{|c|c|c|c|c|c|c|}
\hline Groups & pH & $\begin{array}{c}\text { TSF } \\
(\mu \mathrm{g} F-/ m L)\end{array}$ & $\begin{array}{c}\% \text { SML } \\
\left(\mathrm{kgf} / \mathrm{mm}^{2}\right)\end{array}$ & $\begin{array}{c}\Delta Z \text { (8-bit gray } \\
\text { values) }\end{array}$ & $\begin{array}{c}\mathbf{R a} \\
(\mu \mathrm{m})\end{array}$ & $\begin{array}{c}\text { Sa } \\
(\mu \mathrm{m})\end{array}$ \\
\hline $\begin{array}{c}\text { MSCaTiF } \\
4\end{array}$ & $5.14 \pm 0.60^{\mathrm{A}}$ & $3.52 \pm 1.68^{\mathrm{A}}$ & $\begin{array}{c}15.02 \pm 5.93 \\
\text { A }\end{array}$ & $42.72 \pm 18.15^{\mathrm{A}}$ & $0.43 \pm 0.11^{\mathrm{A}}$ & $0.57 \pm 0.17^{\mathrm{A}}$ \\
\hline $\mathrm{MSTiF}_{4}$ & $6.72 \pm 0.37^{\text {B }}$ & $1.39 \pm 0.60^{\mathbf{B}}$ & $\begin{array}{c}12.47 \pm 3.79 \\
\text { A }\end{array}$ & $40.35 \pm 8.62^{\mathbf{A}}$ & $0.36 \pm 0.12^{\mathrm{A}}$ & $0.46 \pm 0.21^{\mathbf{A}}$ \\
\hline $\mathrm{TiF}_{4}$ & $4.61 \pm 0.10^{\mathrm{C}}$ & $19.76 \pm 9.88^{\mathrm{C}}$ & $\begin{array}{c}31.41 \pm 7.77 \\
\text { в }\end{array}$ & $58.15 \pm 36.97^{\text {B }}$ & $0.58 \pm 0.11^{\mathbf{B}}$ & $\begin{array}{c}0.86 \pm 0.71 \\
\mathbf{A B}\end{array}$ \\
\hline MSCaNaF & $5.79 \pm 0.71^{\mathbf{A B}}$ & $3.25 \pm 0.48^{\mathrm{A}}$ & $\begin{array}{c}11.85 \pm 7.00 \\
\mathbf{A}\end{array}$ & $40.35 \pm 11.63^{\mathrm{A}}$ & $0.39 \pm 0.19^{\mathrm{A}}$ & $0.55 \pm 0.12^{\mathrm{A}}$ \\
\hline $\mathrm{MSNaF}$ & $6.86 \pm 0.69^{\text {B }}$ & $1.16 \pm 0.31^{\mathbf{B}}$ & $\begin{array}{c}14.61 \pm 8.12 \\
\mathbf{A}\end{array}$ & $41.53 \pm 14.53^{\mathrm{A}}$ & $0.40 \pm 0.11^{\mathbf{A}}$ & $0.58 \pm 0.17^{\mathrm{A}}$ \\
\hline $\mathrm{NaF}$ & $4.57 \pm 0.09^{\mathrm{C}}$ & $10.18 \pm 4.34^{\mathbf{D}}$ & $\begin{array}{c}28.01 \pm 8.00 \\
\text { B }\end{array}$ & $45.09 \pm 11.63^{\mathbf{A}}$ & $\begin{array}{c}0.45 \pm 0.16 \\
\mathbf{A B}\end{array}$ & $0.62 \pm 0.26^{\mathrm{A}}$ \\
\hline GC & $4.11 \pm 0.04^{\mathbf{D}}$ & $0.15 \pm 0.02^{\mathbf{E}}$ & $\begin{array}{c}64.49 \pm 9.09 \\
\mathrm{C}\end{array}$ & $199.36 \pm 75.22^{C}$ & $1.02 \pm 0.16^{\mathrm{C}}$ & $1.76 \pm 0.62^{\mathbf{B}}$ \\
\hline $\mathrm{SC}$ & $7.09 \pm 0.09^{\mathrm{E}}$ & $0.16 \pm 0.03^{\mathrm{E}}$ & $3.61 \pm 4.81^{\mathrm{D}}$ & $26.11 \pm 5.81^{\mathbf{A}}$ & $0.29 \pm 0.11^{\mathrm{A}}$ & $0.34 \pm 0.14^{\mathrm{A}}$ \\
\hline
\end{tabular}

Ra: linear roughness; Sa: volumetric roughness; TSF: total soluble fluoride; Different uppercase letters in the same column indicate statistical difference $(\mathrm{p}<0.05)$.

In addition, all experimental nanocomposites were better than $\mathrm{NaF}$ and $\mathrm{TiF}_{4}$ in preventing surface \%SML, $(\mathrm{p}<0.05)$ (Table 2). Micro-CT analyses revealed that with exception of MSCa, all experimental nanocomposites were better than $\mathrm{TiF}_{4}(\mathrm{p}<0.05)$ and similar to $\mathrm{NaF}(\mathrm{p}>0.05)$ in preventing mineral loss within the lesion $(\triangle \mathrm{Z})$ (Table 2 and Figure 4). These data were confirmed by polarized light microscopy (Figure 5), in which different degrees of enamel demineralization were detected in all treatment groups. Photomicrographs observed inFigure 5 show that groups treated with mesoporous-silica nanocomposite in association with fluoride had lower demineralization, similarly as observed in groups treated with $\mathrm{NaF}, \mathrm{TiF} 4$ and sterility control. Greater demineralization was observed in growth control, similarly as observed in the group treated with mesoporous-silica without fluoride.

With respect to $\mathrm{Ra}$ and $\mathrm{Sa}$, the nanocomposites exhibited favorable and similar behavior between them, being similar to the $\mathrm{NaF}$ group $(\mathrm{p}>0.05)$ for $\mathrm{Ra}$ and $\mathrm{Sa}(\mathrm{p}>0.05)$, and to the $\mathrm{TiF}_{4}$ group only for $\mathrm{Sa}(\mathrm{p}>0.05)$ (Table 2). Surface topography findings can be corroborated by SEM images (Figure 6). 

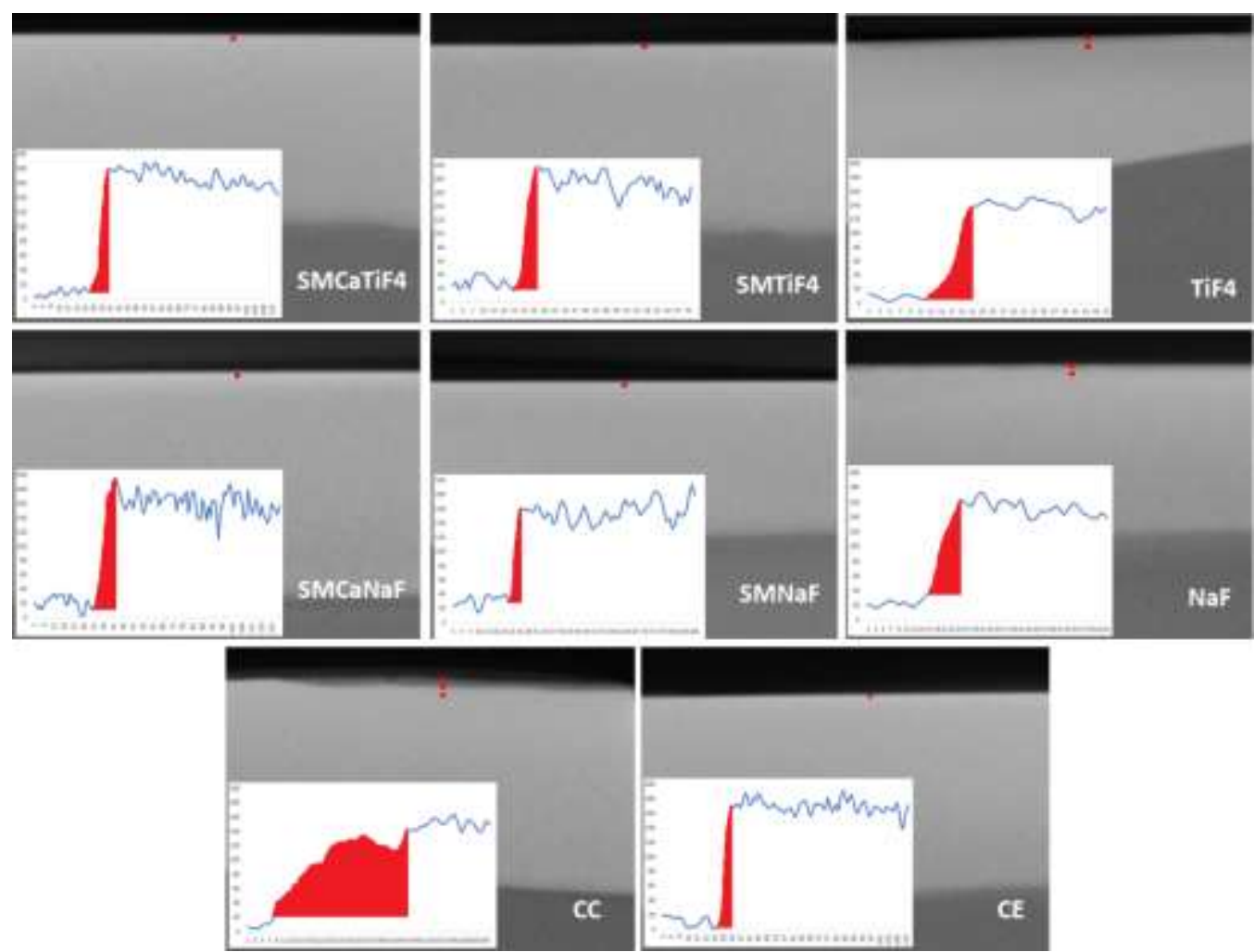

Figure 4: Photomicrograph of enamel surface assessed by micro-CT. The region in red indicates the area and depth of the carious lesion, from where $\Delta \mathrm{Z}$ values were obtained. The unit of measurement on $\mathrm{x}$ axis corresponds to 8-bit gray value, whilst the unit of measurement on y axis corresponds to enamel depth (pixel).
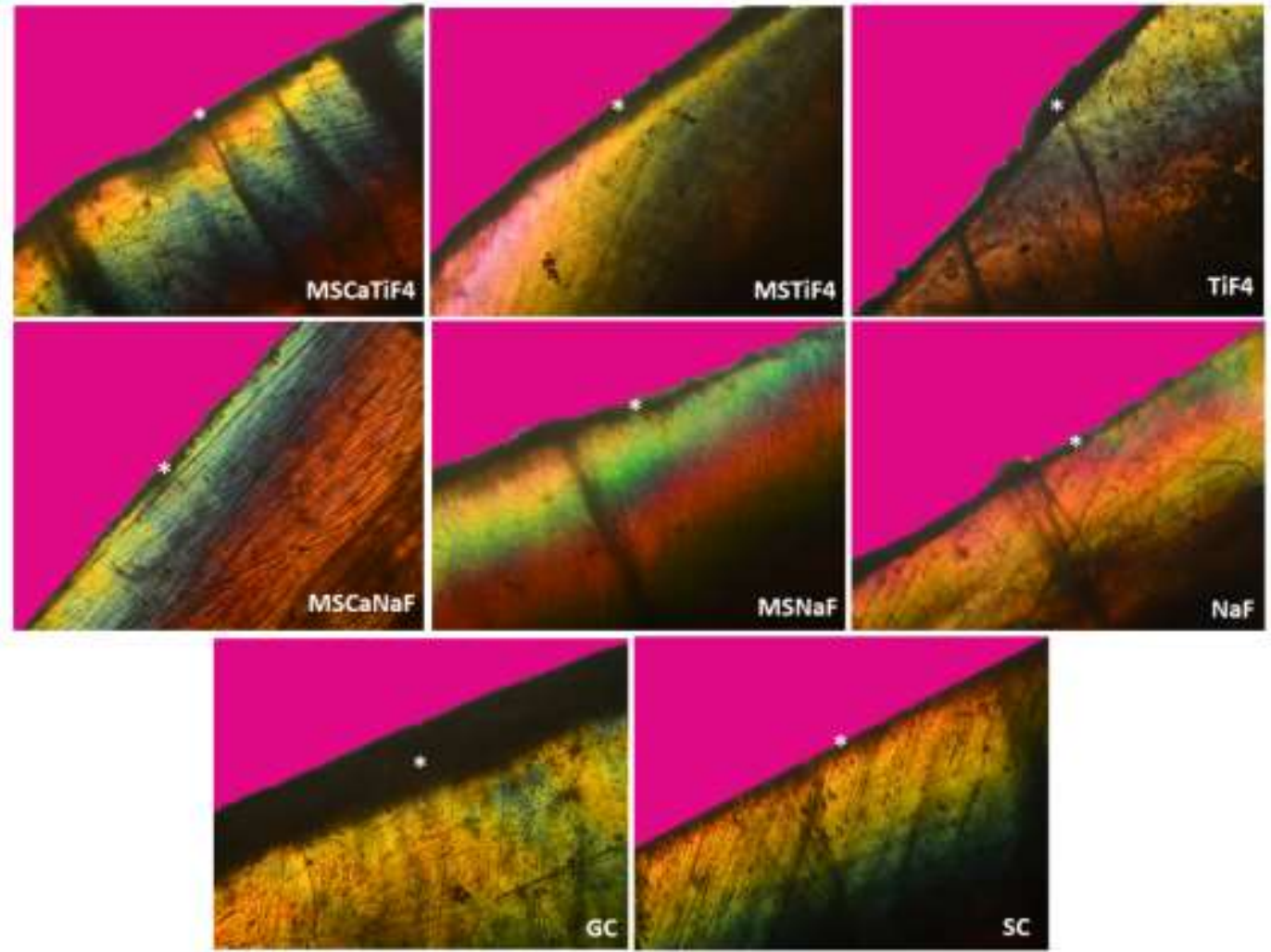

Figure 5: Photomicrograph of enamel surface assessed by polarized light. Demineralization is denoted by the dark area marked with an asterisk $(*)$. 


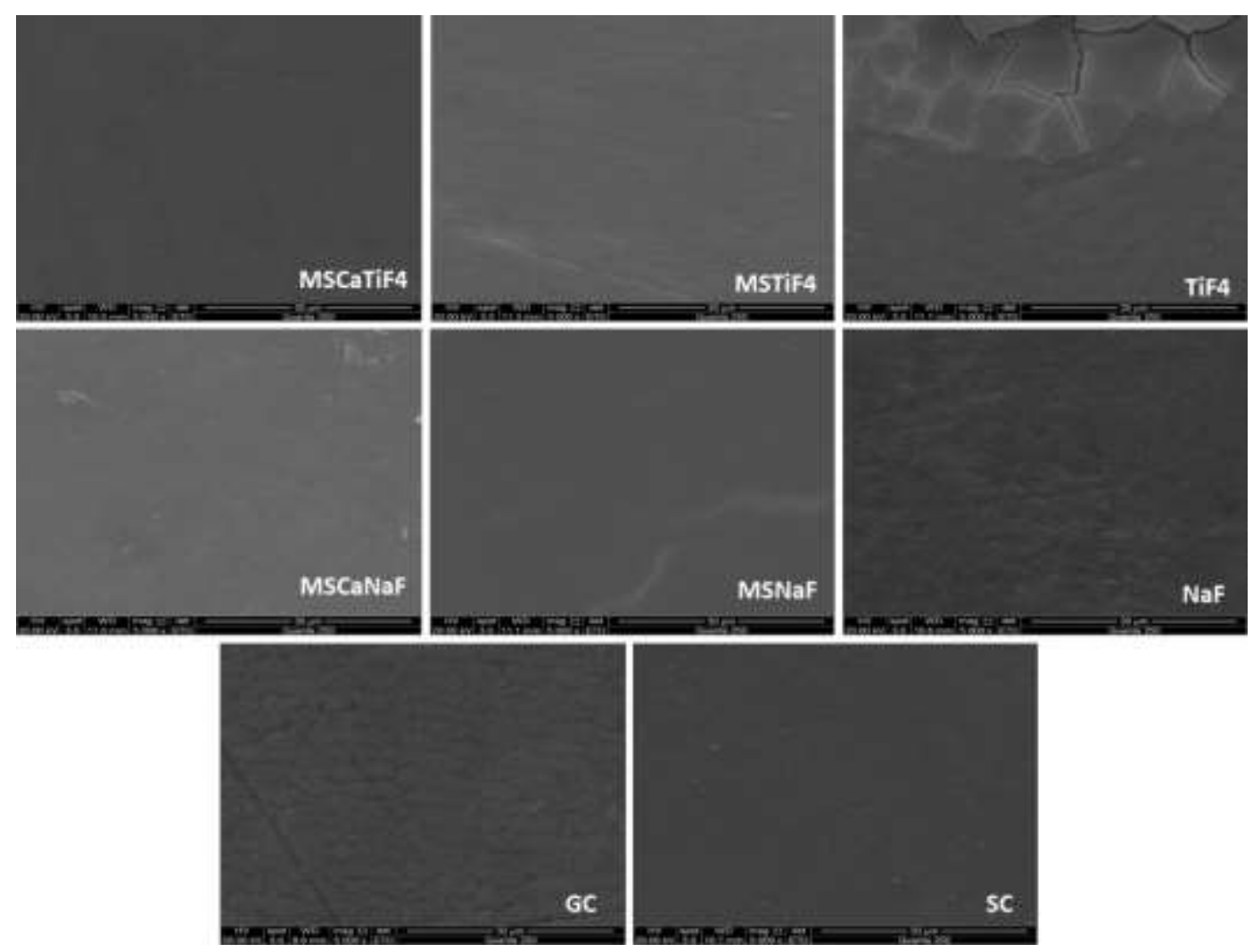

Figure 6: Surface of enamel blocks after treatment assessed by scanning electron microscopy at 5.000x

\section{Discussion}

The present study investigated the effects of new fluoridated products on inhibition of dental enamel demineralization around orthodontic brackets, analyzing the loading capacity of different sources/types of calcium fluorides using MS nanoparticles. There has been no report in the literature on the association of this nanoparticle with fluoridated products as those proposed here, even though the benefits of calcium-doped MS for the production of new materials with different applications have been confirmed, as this particle has mechanical resistance, permeability, thermal stability, and chemical stability $(6,7)$.

The short period of biofilm formation, the use of bovine dental enamel slabs, and constant exposition to sucrose during biofilm development should be acknowledged as relevant aspects that differ from real clinical situation. In order to overcome some limitations of this in vitro assay, the retention of multispecies biofilm was simulated with the use of artificial saliva and orthodontic bracket.

Nevertheless, this study demonstrated that the in vitro multispecies biofilm simulation model was sufficient to reduce $\mathrm{pH}$ to levels below the hydroxyapatite critical level within $24 \mathrm{~h}$. As evidenced by $\%$ SML, micro-CT profile and polarized light images, this cariogenic challenge model resulted in a surface mineral loss. It was noticed that only the preventive application of fluoridated nanocomposites was able to maintain the $\mathrm{pH}$ above the critical level of enamel demineralization, allowing for ionic balance and favoring remineralization. Calcium-doped MS has a high rate of drug release directly proportional to the acidity of the medium (7). According to Ribeiro et al. (6) MS particles are more stable at $\mathrm{pH}$ levels greater than 5, explaining the findings obtained in this study. Moreover, the remineralization conditions could not be developed only in the presence of calcium, because of the effect of the cariogenic challenge associated with the previous application of the test product. This fact justifies the need of the presence of fluoride to optimize the ionic changes in the interface tooth biofilm leading the prevention of surface and subsurface mineral loss.

In this experimental model, as the test products were applied before the cariogenic challenge, the nanocomposites containing calcium and fluoride probably lost their chemical stability, which could have influenced the ionic behavior of fluoride. The presence of an acidic microenvironment, products 
with this association tend to produce better outcomes, thus being indicated for therapeutic use rather than for preventive use as proposed in this study.

Regarding the results of total soluble fluoride, all nanocomposites had better outcomes than conventional $\mathrm{TiF}_{4}$ and/or NaF solutions, where these solutions that released more fluoride into the medium showed poorer protection of the enamel. The nanocomposites may be explained by the high concentration of fluoride adhered to the enamel, as it may reduce demineralization, stopping the release of calcium and phosphate from the enamel into the medium (25).

The development of white spot lesions as consequence of successive dental demineralization exposure during orthodontic treatment may compromise treatment outcomes (1). To minimize that, the complementary use of $\mathrm{TiF}_{4}$ or $\mathrm{NaF}$ solutions may help to maintain oral health, but it is necessary that they are used regularly (2), because of the action of saliva and swallowing will only allow fluoride for only a short period of time. The solutions used in the present study were able to reduce demineralization in a single preventive application, despite differences between the inclusion of nanoparticles with $\mathrm{TiF}_{4}$ and with $\mathrm{NaF}$ associated or not with calcium. On the other hand, when compared to conventional products, nanocomposites reduced demineralization of surface and subsurface lesions adjacent to orthodontic brackets after exposure to the biofilm. $\mathrm{TiF}_{4}$ and $\mathrm{NaF}$ nanocomposites showed the best outcomes, and since these mesoporous silica products can release this composite gradually, the presence of residual fluoride can act as a protective factor against dental demineralization.

The enamel surface of areas around orthodontic brackets is often rough, because biofilm removal in these areas is difficult (3). To minimize such damage, the experimental nanocomposites evaluated herein could be recommended, as they resulted in less rough enamel surfaces (lower Ra and $\mathrm{Sa}$ ), however further in situ and in vivo studies must be conducted to confirm these results.

Dental enamel demineralization analysis by \%SHL and Micro-CT showed that all experimental groups minimized the demineralization process, mainly those treated with MS associated with fluoride. The polarized light microscopy revealed that groups treated with fluoride-enriched nanocomposites exhibited lower demineralized area on the enamel surface, similarly to that observed in $\mathrm{NaF}_{2} \mathrm{TiF}_{4}$ and sterility control groups. Further analyses should consider differences regarding demineralization depth of groups treated with different nanocomposite solutions and their respective controls.

Moreover, as pointed out by SEM, changes on the enamel surface were more evident in the groups MSCa and growth control. On the other hand, enamel integrity was preserved by all of the assessed nanocomposites, and these findings support the therapeutic use of these solutions as complement to caries treatment, $(2,3)$ especially around orthodontic brackets.

Considering both \%SML and micro-CT analyses, nanocomposites reduced the demineralizing capacity when compared to conventional $\mathrm{TiF}_{4}$ and $\mathrm{NaF}$ solutions, and these positive outcomes indicate that these test products seem to be efficient in inhibiting the demineralizing potential of multispecies biofilms, since the inclusion of these composites can produce a synergistic effect, arresting caries progression. Therefore, these test products may be recommended, providing patients on orthodontic treatment with a lower risk of dental caries.

The nanocomposites used in this study could be deemed appropriate for the prevention of dental caries, but, ideally, it would be necessary to verify the mineral content of the enamel after exposure to this test product to assess the presence of calcium and fluoride deposits by future studies. Nevertheless, given the innovative nature of this study, it is also necessary to assess the dose-response effect of these test products in order to elucidate their therapeutic effect, as the association of calcium-doped MS with fluorides had a preventive effect in a single application, which might have extended the release of these composites. Even though cytotoxicity assays were not conducted in the present study, there are no indicative signs in the literature that calcium-doped MS would cause changes in cell integrity (7), which turns this gradual release system into an efficient mechanism for the delivery of drugs or composites.

\section{Conclusion}

A single application of the experimental nanocomposites was able to improve protection against dental enamel demineralization around orthodontic brackets. In general, the association of calciumdoped MS with fluorides had a preventive effect for parameters analyzed there are no differences between these solutions. 


\section{Acknowledgements}

This study was financed in part by the Coordenação de Aperfeiçoamento de Pessoal de Nível Superior - Brasil (CAPES), Finance Code 001; by Conselho Nacional de Ciência e Tecnologia (CNPQ), Finance Code 303535/2016-4; and Fundação de Amparo à Pesquisa do Estado do Rio de Janeiro - Brasil (FAPERJ) process numbers E-26/200.945/2019 and E-26/202.924/2017. We thank Professor Gustavo Miranda Rocha for executed the scanning electronic microscopy analysis and Professor Frederico Barbosa de Sousa for providing equipment for analysis of polarized light. We thank too Mariana Leonel Martins and Amanda Souza Nunes Monteiro for helping carried out the microbiological analysis.

\section{RESUMO}

Este estudo teve como objetivo avaliar o efeito in vitro de uma única aplicação de soluções experimentais de nanocompósitos na prevenção de cárie dentária em braquetes ortodônticos. Os espécimes foram expostos a nanocompósitos de sílica mesoporosa (MS) contendo fluoreto por associação com tetrafluoreto de titânio (TiF4) ou fluoreto de sódio $(\mathrm{NaF})$. Os nanocompósitos também podem conter cálcio e os grupos foram descritos como MSCaTiF4, MSTiF4, MSCaNaF, MSNaF e controles (TiF4 e NaF). Os espécimes foram submetidos à formação de um biofilme multiespécie para gerar um desafio cariogênico. Após $24 \mathrm{~h}$, o pH e a concentração de flúor solúvel total do meio de cultura foram avaliados. A perda mineral foi avaliada pela porcentagem de perda mineral superficial (\% SML), variação do volume mineral $(\Delta \mathrm{Z})$ do esmalte interno e microscopia de luz polarizada (PL). A rugosidade superficial linear $(\mathrm{Ra})$ e volumétrica $(\mathrm{Sa})$ e a microscopia eletrônica de varredura (MEV) foram utilizadas para avaliar a topografia do esmalte. As análises estatísticas foram realizadas considerando $\mathrm{p}$ $<0,05$. MSNaF apresentou o maior valor de $\mathrm{pH}$ do meio de cultura após o desafio cariogênico, semelhante ao MSTiF4. Todas as soluções de nanocompósitos liberaram menos flúor do que seus controles NaF e TiF4 ( $\mathrm{p}<0,05)$. Todas as soluções de nanocompósitos apresentaram\% SML menor em comparação com seus respectivos grupos de controle ( $p<0,05$ ). Ra, Sa e $\Delta \mathrm{Z}$ menores foram observados para os grupos experimentais em comparação ao TiF4 $(\mathrm{p}<0,05)$. Os resultados foram confirmados por análises PL e SEM. As soluções experimentais de nanocompósitos contribuíram para a menor desmineralização do esmalte ao redor dos braquetes ortodônticos.

\section{References}

1. Ren Y, Jongsma MA, Mei L, van der Mei HC, Busscher HJ: Orthodontic treatment with fixed appliances and biofilm formation - a potential public health threat? Clin Oral Invest 2014;18:17111718.

2. Nascimento PL, Fernandes MT, Figueiredo FE, Faria-E-Silva AL. Fluoride-Releasing Materials to Prevent White Spot Lesions around Orthodontic Brackets: A Systematic Review. Braz Dent J. 2016; Jan-Feb;27(1):101-7.

3. Benson PE, Parkin N, Dyer F, Millett DT, Furness S, Germain P. Fluorides for the prevention of early tooth decay (demineralised white lesions) during fixed brace treatment. Cochrane Database Syst Rev. 2013 Dec 12;(12).

4. Li J, Xie X, Wang Y, Yin W, Antoun JS, Farella M, Mei L. Long-term remineralizing effect of casein phosphopeptide-amorphous calcium phosphate (CPP-ACP) on early caries lesions in vivo: a systematic review. J Dent. 2014 Jul;42(7):769-77.

5. Deshayes S, Gref R. Synthetic and bioinspired cage nanoparticles for drug delivery. Nanomedicine (Lond). 2014 Jul;9(10):1545-64.

6. Ribeiro S, Ribeiro T, Ribeiro C, Correia DM, Farinha JPS, Gomes AC, Baleizão C, LancerosMéndez S. Multifunctional Platform Based on Electroactive Polymers and Silica Nanoparticles for Tissue Engineering Applications. Nanomaterials (Basel). 2018 Nov 9;8(11).

7. Gu J, Huang M, Liu J, Li Y, Zhao W, Shi J. Calcium doped mesoporous silica nanoparticles as efficient alendronate delivery vehicles. New Journal of Chemistry, 2012, v. 36, p. 1717-1720.

8. Zhang JF, Wu R, Fan Y, Liao S, Wang Y, Wen ZT, Xu X. Antibacterial dental composites with chlorhexidine and mesoporous silica. J Dent Res. 2014 Dec;93(12):1283-9.

9. Yan H, Yang H, Li K, Yu J, Huang C. Effects of Chlorhexidine-Encapsulated Mesoporous Silica Nanoparticles on the Anti-Biofilm and Mechanical Properties of Glass Ionomer Cement. Molecules. 2017 Jul 21;22(7):1225. 
10. Seneviratne CJ, Leung KC, Wong CH, Lee SF, Li X, Leung PC, Lau CB, Wat E, Jin L. Nanoparticle-encapsulated chlorhexidine against oral bacterial biofilms. PLoS One. 2014 Aug 29;9(8):e103234.

11. Jung JH, Park SB, Yoo KH, Yoon SY, Bae MK, Lee DJ, Ko CC, Kwon YH, Kim YI. Effect of different sizes of bioactive glass-coated mesoporous silica nanoparticles on dentinal tubule occlusion and mineralization. Clin Oral Investig. 2019 May;23(5):2129-2141.

12. Jung JH, Kim DH, Yoo KH, Yoon SY, Kim Y, Bae MK, Chung J, Ko CC, Kwon YH, Kim YI. Dentin sealing and antibacterial effects of silver-doped bioactive glass/mesoporous silica nanocomposite: an in vitro study. Clin Oral Investig. 2019 Jan;23(1):253-266.

13. Tian L, Peng C, Shi Y, Guo X, Zhong B, Qi J, Wang G, Cai Q, Cui F. Effect of mesoporous silica nanoparticles on dentinal tubule occlusion: an in vitro study using SEM and image analysis. Dent Mater J. 2014;33(1):125-32.

14. Canto FMT, Alexandria AK, Vieira TI, Justino IBDS, Cabral LM, Silva RFD, Maia LC. Comparative Effect of Calcium Mesoporous Silica Versus Calcium and/or Fluoride Products Against Dental Erosion. Braz Dent J. 2020 Mar-Apr;31(2):164-170

15. Canto FMT, Alexandria AK, Justino IBDS, Rocha GM, Cabral LM, Ferreira RDS, Pithon MM, Maia LC. The use of a new calcium mesoporous silica nanoparticle versus calcium and/or fluoride products in reducing the progression of dental erosion. J Appl Oral Sci. 2020;28:e20200131.

16. Alexandria AK, Nassur C, Nóbrega CBC, Valença AMG, Rosalen PL, Maia LC. In situ effect of titanium tetrafluoride varnish on enamel demineralization. Braz Oral Res. 2017a; Nov 6;31:e86.

17. Thierens LAM, Moerman S, Elst CV, et al. The in vitro remineralizing effect of CPP-ACP and CPP-ACPF after 6 and 12 weeks on initial caries lesion. J Appl Oral Sci. 2019, May 20;27:e20180589.

18. Hara AT, Queiroz CS, Paes Leme AF, Serra MC, Cury JA. Caries progression and inhibition in human and bovine root dentine in situ. Caries Res. 2003, 37:339-344.

19. Katara, G., Hemvani, N., Chitnis, S., Chitnis, V., \& Chitnis, D. S. Surface disinfection by exposure to germicidal UV light. Indian J Med Microbiol. 2008; 26(3): 241-242.

20. CLSI. Performance Standards for Antimicrobial Susceptibility Testing; Twenty-Second Informational Supplement. CLSI document M100-S22. Wayne PA in Clinical and Laboratory Standards Institute, 2012.

21. Amaechi, B. T., Higham, S. M., \& Edgar, W. M. Techniques for the production of dental eroded lesions in vitro. J Oral Rehabil. 1999, 26(2): 97-102.

22. Passalini P, Fidalgo TK, Caldeira EM, Gleiser R, Nojima Mda C, Maia LC. Preventive effect of fluoridated orthodontic resins subjected to high cariogenic challenges. Braz Dent J. 2010; 21(3):2115.

23. Cury, J. A., Rebelo, M. A. B., Del Bel Cury, A. A., Derbyshire, M. T. V. C., \& Taubchoury, C. P. M. Biochemical Composition and Cariogenicity of Dental Plaque Formed in the Presence of Sucrose of Glucose and Fructose. Caries Res. 2000, 34: 491-497.

24. Nakata K, Nikaido T, Nakashima S, Nango N, Tagami J. An approach to normalizing micro$\mathrm{CT}$ depth profiles of mineral density for monitoring enamel remineralization progress. Dent Mater J. 2012;31(4):533-40

25. Nóbrega DF, Leitão TJ, Cury JA, Tenuta LMA. Fluoride Binding to Dental BiofilmBacteria: Synergistic Effect with Calcium Questioned. Caries Res. 2018 Jun 6;53(1):10-15. 